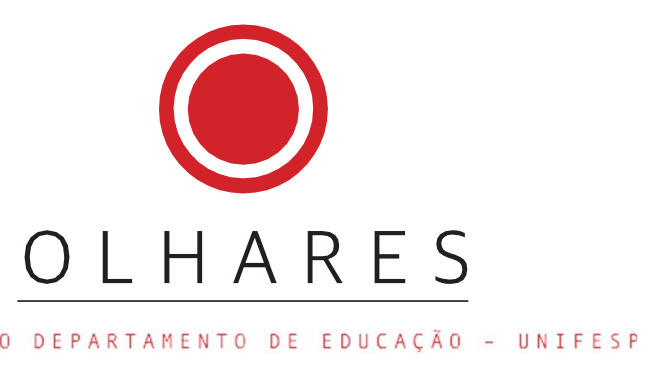

\title{
APRENDENDO A SONHAR COM CIEJA CAMPO LIMPO: a inclusão escolar através de uma metodologia na perspectiva freiriana
}

\author{
APRENDIENDO A SOÑAR CON CIEJA CAMPO LIMPO: inclusión escolar a \\ través de una metodología desde la perspectiva freiriana
}
LEARNING TO DREAM WITH CIEJA CAMPO LIMPO: school inclusion through a methodology from the freirian perspective

\author{
Martha Milene Fontenelle Carvalho \\ Universidade Regional do Cariri (URCA) \\ martha.fontenelle@urca.br \\ Rosane Santos Gueudeville \\ Universidade Regional do Cariri (URCA) \\ rosane.gueudeville@urca.br
}

\begin{abstract}
Resumo: É necessário pensar as práticas educativas com foco em ações mais humanas, democráticas e equitativas, que ultrapassem os muros ainda resistentes de uma educação bancária e homogênea, que não valoriza a diversidade e liberdade humana. O cenário exige transformação. Diante disso, fazem-se necessárias atitudes que promovam a inclusão educacional, possibilitando que todas as pessoas participem da vida em sociedade, assegurando o acolhimento à diversidade humana e aceitação das diferenças e peculiaridades dos educandos público-alvo da Educação Especial. Assim, o objetivo desta investigação foi compreender as práticas pedagógicas no CIEJA Campo Limpo que dialogam com uma perspectiva freiriana e inclusiva. Tratou-se de um estudo de avaliação do Estado do Conhecimento (ou Estado da Arte). Do ponto de vista do corpus empírico, tratou-se de uma pesquisa documental, alicerçada metodologicamente na Análise de Conteúdo. Os resultados foram obtidos através do levantamento sistematizado de literatura, realizado por meio do Catalogo de teses e Dissertações da CAPES, através dos descritores: CIEJA e inclusão. Foi encontrado um total de 24 dissertações, utilizando-se como critérios de inclusão estudos que apresentassem como campo empírico o CIEJA Campo Limpo e/ou tivessem a inclusão como eixo de discussão; e como critérios de exclusão, estudos que não tivessem sido realizados no Centro Integrado mencionado. Após a leitura inicial dos respectivos resumos e das descrições metodológicas (em capítulos específicos) apenas 4 (quatro) tratavam diretamente do CIEJA Campo Limpo. Os resultados apontaram que as práticas pedagógicas ancoradas nas concepções freirianas conduzem para a libertação e para uma educação emancipatória e possibilitam pensar o processo de transformação da realidade, tão indispensável ao contexto atual.
\end{abstract}

Plavras-chave: Paulo Freire. Inclusão educacional. EJA. 


\title{
Resumen.
}

Es necesario pensar en prácticas educativas con foco en acciones más humanas, democráticas y equitativas, que vayan más allá de los muros aún resistentes de una educación bancaria y homogénea, que no valora la diversidad y la libertad humana. El entorno requiere transformación. Por tanto, son necesarias actitudes que promuevan la inclusión educativa, que permitan a todas las personas participar de la vida en sociedad, asegurando la aceptación de la diversidad humana y la aceptación de las diferencias y peculiaridades de los alumnos destinatarios de Educación Especial. Así, el objetivo de esta investigación fue comprender las prácticas pedagógicas en CIEJA Campo Limpo que dialogan con una perspectiva freiriana e inclusiva. Fue un estudio para evaluar el estado del conocimiento (o el estado del arte). Desde el punto de vista del corpus empírico, fue una investigación documental, metodológicamente basada en el Análisis de Contenido. Los resultados se obtuvieron a través de una encuesta bibliográfica sistemática, realizada a través del Catálogo de Tesis y Disertaciones CAPES, a través de los descriptores: CIEJA e inclusión. Se encontraron un total de 24 disertaciones, utilizando como criterio de inclusión estudios que presentaban a CIEJA Campo Limpo como campo empírico y / o tenían la inclusión como eje de discusión; y como criterio de exclusión, estudios que no se hubieran realizado en el mencionado Centro Integrado. Tras la lectura inicial de los respectivos resúmenes y descripciones metodológicas (en capítulos específicos), solo 4 (cuatro) trataron directamente de CIEJA Campo Limpo. Los resultados mostraron que las prácticas pedagógicas ancladas en las concepciones de Freire conducen a la liberación y a una educación emancipadora y permiten pensar en el proceso de transformación de la realidad, tan esencial en el contexto actual.

Palabras clave: Paulo Freire. Inclusión educativa. EJA.

\begin{abstract}
It is necessary to think about educational practices with a focus on more humane, democratic and equitable actions, which go beyond the still resistant walls of a banking and homogeneous education, which does not value diversity and human freedom. The setting requires transformation. Therefore, attitudes that promote educational inclusion are necessary, enabling all people to participate in life in society, ensuring the acceptance of human diversity and acceptance of differences and peculiarities of students target audience of Special Education. Thus, the objective of this investigation was to understand the pedagogical practices in CIEJA Campo Limpo that dialogue with a freirian and inclusive perspective. It was a study to assess the State of Knowledge (or State of the Art). From the point of view of the empirical corpus, it was a documental research, methodologically based on Content Analysis. The results were obtained through a systematic literature survey, carried out through the CAPES Theses and Dissertations Catalog, through the descriptors: CIEJA and inclusion. A total of 24 dissertations were found, using as inclusion criteria studies that presented CIEJA Campo Limpo as an empirical field and/or had inclusion as the axis of discussion; and as exclusion criteria, studies that had not been carried out in the aforementioned Integrated Center. After the initial reading of the respective abstracts and methodological descriptions (in specific chapters), only 4 (four) dealt directly with CIEJA Campo Limpo. The results showed that the pedagogical practices anchored in Freire's conceptions lead to liberation and to an emancipatory education and make it possible to think about the process of transforming reality, so essential to the current context.
\end{abstract}

Keywords: Paulo Freire. Educational inclusion. EJA. 


\section{Introdução}

A educação faz sentido porque as mulheres e homens aprendem que através da aprendizagem podem fazerem-se e refazerem-se, porque mulheres e homens são capazes de assumirem a responsabilidade sobre si mesmos como seres capazes de conhecerem. (FREIRE, 2004, p. 15).

A educação, seja a nível nacional ou no contexto mundial, hoje presume um modelo de escola que esteja ancorado no paradigma da inclusão, fazendo-se uma ressalva quanto às recentes mudanças observadas no cenário brasileiro, de que são exemplos as declarações

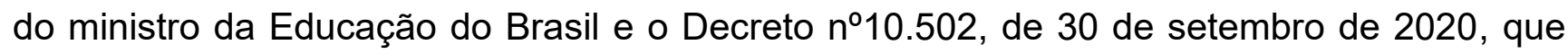
vão na contramão da inclusão e diversidade.

Nesse processo, a escola e seus docentes são convidados a enfrentarem o grande desafio de acolher, com qualidade, a toda a diversidade de estudantes, pois não basta apenas possibilitar que os alunos tenham acesso à escola: torna-se basilar que todos os alunos verdadeiramente aprendam. Igualmente, são necessárias profundas mudanças na organização e funcionamento das unidades escolares e nas práticas pedagógicas utilizadas.

Logo, as escolas, seus gestores e professores precisam se organizar, para não só acolherem os estudantes, mas oferecerem a eles condições favoráveis de aprendizagem, de forma que todos tenham as mesmas oportunidades de acesso e assimilação dos conteúdos curriculares. Assim, a organização de estratégias e metodologias diferenciadas são fundamentais, de modo a atender igualmente a todos os estudantes, independentemente de sua condição social, intelectual, sensorial, comportamental, física ou qualquer outra natureza.

Nesse sentido, as escolas têm sido provocadas a realizarem práticas pedagógicas mais sintonizadas com as transformações em curso, nas diferentes esferas sociais: econômicas, tecnológicas, culturais, educacionais. Toma-se como exemplo o CIEJA Campo Limpo, criado em 1998, com sua proposta inovadora para a Educação de Jovens e Adultos (EJA), adotando, desde o princípio, as concepções freirianas como direcionamento das suas práticas. Localizado na zona sul da capital paulista, no Capão Redondo, bairro considerado um dos mais violentos da cidade, o CIEJA Campo Limpo vem cumprindo um papel preponderante, de resistência e transformação social, dentre a rede de CIEJAs do município de São Paulo.

No CIEJA Campo Limpo, o currículo é pautado e construído de maneira coletiva, na relação cotidiana interativa entre docentes e discentes. A partir de assuntos propostos no debate em sala de aula, os educadores organizam conteúdos e trocam experiências e vivências pessoais, passando as orientações devidas em cada área de conhecimento e adotando as flexibilizações necessárias. O Centro conta com horários flexíveis e possibilidade 
de reposição de aulas, entre outras práticas reconhecidamente importantes no processo de inclusão de jovens e adultos, como também das pessoas com deficiência e idosos em geral. O centro é uma referência nacional no campo das políticas e práticas da EJA.

O objetivo desta investigação foi compreender as práticas pedagógicas no CIEJA Campo Limpo que dialogam com a perspectiva freiriana e inclusiva. É uma pesquisa de base bibliográfica que, conforme Severino (2007, p. 122), "utiliza-se de dados ou de categorias já trabalhados por outros pesquisadores e devidamente registrados". A abordagem é qualitativa, pressupondo a subjetividade dos pesquisadores na análise dos fenômenos observados e dados coletados.

\section{Na perspectiva da educação inclusiva: subsídios para liberdade, respeito e inclusão}

Palavra não é privilégio de algumas pessoas, mas o direito de todos. (FREIRE, 2013, p.80)

Nas últimas décadas, o Brasil tem se voltado à promoção de um processo de inclusão dos estudantes público-alvo da Educação Especial nas escolas regulares, especialmente após os compromissos internacionais assumidos pelas políticas públicas nacionais, endossando a Declaração Mundial sobre Educação para Todos e a Declaração de Salamanca (UNESCO, 1990; 1994), assim como a Convenção Internacional dos Direitos das Pessoas com Deficiência (Decreto $n^{\circ}$ 6.949, 2009). Internamente, foi adotada a Política Nacional de Educação Especial na Perspectiva da Educação Inclusiva (BRASIL, 2008) e, mais recentemente, a Lei Brasileira de Inclusão (BRASIL, 2015).

Durante muito tempo persistiu, e ainda se faz presente, o modelo de escolarização referenciado a partir de um aluno padrão, regulado e normatizado, cujo corpo dócil é capaz de responder às expectativas. Neste modelo, tudo o que foge do padrão estipulado é penalizado, através da disciplina, e a conduta é encaixada em grupos classificatórios: boa ou má, correta ou errada. Entretanto, o aparecimento de movimentos reivindicatórios abarcando outros personagens, como aqueles que apresentam algum tipo de deficiência, impôs um (re) pensar das práticas exercidas no contexto educacional, principalmente quanto à promoção da inclusão escolar.

Constata-se que as políticas públicas ofertadas a esse público têm, de alguma forma, possibilitado mudanças dos discursos oficiais, estes que foram construídos ao longo da história, visando segregar e excluir. Compreende-se, assim, que "a ação afirmativa é uma política de igualdade que visa garantir direitos a grupos historicamente excluídos de sua 
cidadania plena" (MANTOAN; BARANAUSKAS; CARICO, 2008, p. 104). Vale a pena ressaltar, portanto, que a implementação das políticas públicas inclusivas no Brasil são fruto de movimentos sociais, deflagrados por grupos minoritários que, por décadas, têm sido excluídos do acesso a bens culturais e serviços públicos.

De acordo com os dados do Censo Demográfico Brasileiro de 2010, existem 45,6 milhões de pessoas que se autodeclararam ter pelo menos um tipo de deficiência: visual, auditiva, motora ou mental/intelectual, o que representa $23,9 \%$ da população brasileira. Em decorrência de todos os esforços, a essas pessoas estão sendo oferecidas maiores possibilidades para conviver com suas diferenças e limitações. No que tange à sua inclusão no ambiente escolar, observa-se um crescimento no número de matrículas desses alunos, especialmente na Educação de Jovens e Adultos,

Mas apesar do estabelecimento de leis e implementação de políticas que contemplam os objetivos da educação inclusiva, muitos estudantes com deficiência ainda convivem com a exclusão. Ao analisarmos o contexto da educação especial, percebe-se ainda o distanciamento entre as políticas e a realidade, quanto ao acesso desses sujeitos, pois aqueles que conseguem ingressar ainda se deparam com muitas barreiras, delineando, de forma negativa, a realidade do ensino brasileiro (FACCI; MEIRA; TULESKI,2011).

Entre as barreiras, está a permanência da exigência, por parte de muitas escolas, de um aluno padrão, que atenda todas as demandas pedagógicos-educacionais; a hierarquização dos conhecimentos e adoção de sequências rígidas para se trabalhar os conteúdos; as competências e habilidades previamente estabelecidas; tudo isso contribuindo para que tais estudantes abandonem os estudos.

Assim, os discursos que defendem a inclusão dos alunos com deficiência apontam para direitos que lhes foram negados ao longo da história, mas também para falhas nas práticas e estruturas inclusivas. Nesse sentido, tais práticas devem ser pautadas tendo como referência as lutas pela garantia desses direitos e o combate à invisibilidade institucionalizada, de negação da condição de diferença/deficiência, ancorando-se verdadeiramente nos princípios da liberdade, respeito e inclusão social.

\section{Influências de Paulo Freire para uma educação emancipatória: o diálogo com a liberdade e inclusão}

Ninguém nasce feito, é experimentando-nos no mundo que nós nos fazemos. (FREIRE, 1997, p.40) 
Faz-se necessário pensar as práticas educativas com foco em ações mais humanas, democráticas e justas, que ultrapassem os muros ainda resistentes de uma educação bancária e homogênea, que não valoriza a diversidade e liberdade humana. A construção de uma sociedade verdadeiramente inclusiva perpassa pelos questionamentos que estão relacionados à realidade opressora ainda dominante, que não promove o diálogo e emancipação dentro dos espaços escolares regulares, muitas vezes promotores da construção de obstáculos e barreiras, que precisam urgentemente serem transpostas.

Como exemplo de enfrentamento dessa situação, foram encontradas, durante a realização deste estudo, dados que fazem melhor compreender as práticas pedagógicas do CIEJA Campo Limpo, que dialogam, de forma intensa e produtiva, com a perspectiva freiriana e inclusiva de educação. Contrapondo-se às ações realizadas nos espaços educacionais que ainda desconsideram a diferença e continuam contribuindo para a exclusão social.

Os achados da pesquisa realizada por Toledo (2017) apontam, como razões que fazem estudantes adolescentes abandonarem a escola regular: a ausência de uma diálogo entre o currículo escolar e as expectativas para a inserção mercado de trabalho; o conteúdo escolar apresentado de maneira desigual e fragmentada; a falta de aproximação dos conteúdos com a realidade cotidiana e as necessidades prementes dos adolescentes; a infrequência às aulas, cujos motivos não são investigados pela escola, e que leva os alunos a terem grandes dificuldades para acompanhar as matérias.

Medeiros (2018) investiga se a experiência na Educação de Jovens e Adultos, ofertada pelo CIEJA Campo Limpo, tem colaborado para uma formação que privilegie a conscientização acerca da condição social e a ressignificação das trajetórias de seus alunos (com deficiência e sem deficiência), ao propiciar condições para o desenvolvimento do sentimento de pertença, de identidade social e formação política. Os resultados evidenciam que as práticas desses estudantes no CIEJA, assim como os percursos que os levaram até lá, além do seu engajamento nos movimentos de resistência e luta pela aquisição do direito à educação, levaram-nos a expressarem o desejo de desenvolvimento de capacidade leitora, escritora e de reconhecimento de seu lugar nos espaços sociais da escola e da comunidade.

Assim, o Centro cumpre um papel agregador e articulador, constituindo-se como referência a partir do seu modelo institucional e pedagógico, sempre ancorados nas concepções freirianas. Para Freire, práticas pedagógicas que não são neutras, nem opressoras, e que conduzem para a libertação, para uma educação emancipatória, são fundamentais para se pensar o processo de transformação da realidade, tão indispensável no contexto atual: 
[...] que é mesmo a minha neutralidade senão a maneira cômoda, talvez, mas hipócrita, de esconder minha opção ou meu medo de acusar a injustiça? "Lavar as mãos" em face da opressão é reforçar o poder do opressor, é optar por ele. Como posso ser neutro diante da situação, não importa qual seja ela, em que o corpo das mulheres e dos homens vira puro objetivo de espoliação e de descaso? (FREIRE, 1996, p. 112)

É preciso refletir sobre a ausência de uma educação de qualidade para todos, e discutir a permanência de processos educacionais que negam direitos, oprimem e excluem, reforçando o poder dominante opressor. Essa discussão, sob uma perspectiva freiriana, possibilita uma aproximação real com a inclusão de pessoas com deficiência, já que o debate abre portas largas e sem ferrolhos, para se chegar ao diálogo, autonomia, generosidade, respeito e esperança, elementos fundamentais para vencer um contexto ainda tão excludente.

Costa e Turci (2011, p. 3763), falando sobre pessoas com deficiência, dizem que elas "foram segregados por meio de práticas homogeneizadoras construídas e delimitadas a partir de um padrão de normalidade referenciado pelo princípio da individualidade e da competitividade". Para superar isso, as reflexões e diálogos estabelecidos por Freire conduzem a uma conscientização crítica sobre o modo de agir na prática social e educacional, buscando transpor barreiras que permeiam aquele padrão, rumo a uma educação que considere, antes, a inclusão e o respeito à diversidade.

É imperioso, no pensar e fazer inclusivo, construir pontes para a transformação das desigualdades sociais, em todas as áreas. A escola apresenta-se, então, enquanto espaço para construção da libertação. Os debates, diálogos, discussões que são gerados no ambiente escolar podem proporcionar uma reflexão crítica sobre a realidade social e sobre os caminhos do mundo, de que igualmente fazem parte alunos e professores.

O fracasso e a evasão escolar, tão presentes nas preocupações de Freire (2001), atingem fortemente as pessoas com deficiência. Ainda hoje são recorrentes as práticas de preconceito e intolerância, que impedem a permanência desses alunos na escola, com alguma qualidade. E assim, em muitas situações eles acabam desistindo de concluir os estudos.

As crianças populares brasileiras não se evadem da escola, não a deixam porque querem. As crianças populares brasileiras são expulsas da escola - não, obviamente, porque esta ou aquela professora, por uma questão de pura antipatia pessoal, expulse estes ou aqueles alunos ou os reprove. É a estrutura mesmo da sociedade que cria uma série de impasses e de dificuldades, uns em solidariedade com os outros, de que resulta obstáculos enormes para as crianças populares não só chegarem à escola, mas também, quando chegam, nela ficarem e nela fazerem o percurso que têm direito (FREIRE, 2001, p.35). 
O cenário exige transformação. Fazem-se necessárias atitudes que promovam a inclusão educacional, possibilitando que todas as pessoas participem da vida em sociedade, assegurando o acolhimento à diversidade humana e a aceitação das diferenças peculiares dos educandos que são público-alvo da Educação Especial. A educação para a transformação é resultado de um trabalho em conjunto, que perpassa por professores, alunos, gestores, comunidade, considerando-se que na troca de conhecimentos e diálogos é que se torna possível agir e intervir no mundo, visando promover a libertação de todas as pessoas que se encontram em situação de opressão.

Somente quando os oprimidos descobrem, nitidamente, o opressor, e se engajam na luta organizada por sua libertação, começam a crer em si mesmos, superando, assim, sua "conivência" com o regime opressor. Se esta descoberta não pode ser feita em nível puramente intelectual, mas da ação, o que nos parece fundamental, é que esta não se cinja a mero ativismo, mas esteja associada a sério empenho de reflexão, para que seja práxis. (FREIRE, 1987, p. 29).

É preciso engajamento coletivo, debate, reflexão. Pensar a educação em uma perspectiva freiriana é pensar no enfrentamento de desigualdades sociais, na compreensão e respeito às particularidades do outro, às suas individualidades e necessidades, na transposição e superação de preconceitos, em suas mais variadas formas. Freire dialoga com estratégias de trabalho que reconheçam as diferenças e utilizem metodologias de ensino que compreendam estratégias para diminuição das desigualdades.

É preciso, portanto, partindo da perspectiva de educação freiriana, repensar as práticas inclusivas dentro do contexto da sala de aula, que não deve ser um espaço para o mero depósito de conteúdos. É preciso fazer das práticas caminhos para a transformação, rumo ao desenvolvimento de potencialidades criadoras, criativas e críticas, posto que "[...] ensinar é um ato criador, um ato crítico e não mecânico" (FREIRE, 2013, 81).

A prática em Paulo Freire caminha, portanto, com a educação para todos, é dialógica e atuante na quebra de preconceitos e restrições que impedem o acesso igualitário e a permanência na escola de todos os educandos. A transformação das práticas que permeiam o contexto escolar, ainda homogeneizadores e excludentes, devem mobilizar e inquietar os educadores, para que possam gerar a conscientização necessária para a transformação da sociedade.

A inclusão, nesse contexto, deve apresentar-se enquanto resultado de uma educação democrática, participativa, que transpõe práticas tradicionais que consideram apenas um tipo de aluno, um único modelo, avessas à compreensão da diversidade. Para Mantoan (2003, p. 32): 
A inclusão é produto de uma educação plural, democrática e transgressora. Ela provoca uma crise escolar, ou melhor, uma crise de identidade institucional, que por sua vez, abala a identidade dos professores e faz com que seja ressignificada a identidade do aluno. O aluno da escola inclusiva é outro sujeito, que não tem uma identidade fixada em modelos ideais, permanentes, essenciais.

Freire está intimamente relacionado com o diálogo estabelecido em torno da educação inclusiva, trazendo relevantes contribuições para a construção de uma educação de qualidade para todos, através de uma prática reflexiva e comprometida, que considera a importância da vivência coletiva, do acolhimento e respeito às diferenças. É preciso, portanto, aproximar-se de Paulo Freire, quando se fala em inclusão escolar, quando se buscam escolas regulares que trabalham com práticas inclusivas e emancipatórias.

\section{Práticas de inclusão e emancipação no CIEJA Campo Limpo}

É fundamental diminuir a distância entre o que se diz e o que se faz, de tal forma que, num dado momento, a tua fala seja a tua prática.

(FREIRE, 2003, p.61)

Com o objetivo de apresentar um contexto escolar cujas práticas dialogam com a perspectiva freiriana e inclusiva, optou-se pelo compartilhamento do trabalho realizado na escola CIEJA Campo Limpo. Para isso, foi utilizado o livro Volta ao mundo em treze escolas (GRAVATÁ André, et. al.,2013), que traz experiências de professores que viajaram o mundo para encontrar iniciativas inovadoras de educação, encontrando práticas inspiradoras em inúmeros países, incluindo o Brasil. O livro oportunizou, então, uma viagem até o Centro Integrado de Educação de Jovens e Adultos (CIEJA) do Campo Limpo, no distrito de Capão Redondo, em São Paulo.

O Capão Redondo é uma região periférica da capital paulistana, marcada pela violência. Um dos alunos do CIEJA Campo Limpo, que costuma chegar por volta das cinco da madrugada na escola, vem direto do trabalho em um restaurante. Ele espera a abertura dos portões, às $7 \mathrm{~h} 30$, e já foi assaltado na porta da instituição. De acordo com os moradores, o clima de tensão diminuiu muito ao longo dos anos, mas o bairro ainda é considerado um dos mais violentos da cidade. (GRAVATÁ et. al. 2013, p.32)

Mesmo em meio a um contexto marcado pela violência, a escola encontra-se de portas abertas para todas as pessoas, a qualquer momento do dia. Ali encontram-se professores e alunos que dialogam e trabalham juntos, valorizando $o$ respeito, acolhimento $e$ reconhecimento do outro, independentemente de onde venha. A escola também promove ações com grande impacto local. São muitos alunos que participam dessas ações, direcionadas para intervenções no contexto em que vivem, discutindo os problemas e 
necessidades da comunidade. As ações e iniciativas abrangem áreas diversas, como a discussão sobre aproveitamento de sobras de legumes e frutas, instalação de lixeiras comunitárias, plantio de árvores, criação de hortas, entre outras

Assim, a escola avança nas suas relações, na interação com a coletividade e na aprendizagem, evidenciando uma educação calcada nas ideias de Freire, que transpõe os muros da escola, pensa e transforma não apenas a si, mas toda uma comunidade. Nesse caminhar coletivo, que abraça e envolve a vida de muitos, a escola tem um foco também direcionado para o acolhimento e a diversidade, numa perspectiva inclusiva, como ressaltam Gravatá et al. (2013, p.38):

[...] um dos pontos de partida da escola é a inclusão. CIEJA Campo Limpo recebe 35 alunos surdos, 18 cegos, 22 cadeirantes e muletantes e 200 deficientes intelectuais, a coordenadora ressalta que isso é apenas o reflexo de que o ponto de partida do projeto é a inclusão.

O CIEJA Campo Limpo promove uma mesma educação de qualidade para todos, independente se os alunos apresentam algum tipo de deficiência. Assim, os alunos, com as suas especificidades e suas mais variadas deficiências, contemplam na escola a esperança de um futuro promissor, com sua inclusão e inserção no contexto social. Há aqueles que encontram na escola um espaço de apoio e afetividade, e mesmo finalizando os estudos, passam a frequentar a escola como se ainda fossem alunos:

Parte dos alunos com deficiência participa da mesma dinâmica de módulos explicada anteriormente, com os demais alunos da escola. Outra parte visita o CIEJA Campo Limpo apenas dois dias por semana, em encontros no período da tarde. Há aqueles que, como Ronildo, 24 anos, deficiente visual desde os 5 anos devido a complicações de uma meningite, voltam quase diariamente, mesmo depois do fim do curso. Para Ronildo, a escola deixou de ser um lugar de passagem para se tornar uma sala de estar, um ponto de encontro. (GRAVATÁ André, et. al. 2013, p.39)

Nesse processo de inclusão, cita-se ainda o Café Terapêutico, evento criado pelo CIEJA Campo Limpo, que promove o diálogo entre pais e mães de estudantes com deficiência. Os encontros são semanais e possibilitam a troca de experiências e discussão sobre a compreensão e o respeito às diferenças, trazendo como tema: "A inclusão que temos e a inclusão que queremos". Em 2013, a iniciativa foi reconhecida nacionalmente.

Assim, as práticas na escola CIEJA Campo Limpo têm dialogado com uma perspectiva freiriana e inclusiva, contemplando valores que demonstram respeito, responsabilidade, bemestar, confiança, cuidado, transformação, liberdade e acolhimento; elementos preciosos quando se trata do ensinar e do aprender em Paulo Freire. 


\section{Considerações finais}

A partir do estudo realizado, compreende-se a necessidade de se incluir os ensinamentos deixados por Freire nas práticas educativas que pretendam conscientizar sobre o respeito à diversidade, as necessidades e individualidades dos diversos estudantes. As práticas que transpõem a opressão e a exclusão de pessoas fora das normativas socais não podem mais ficar à margem do processo de ensino e aprendizagem, é preciso emancipar e municiar o educando com deficiência, frente às desigualdades e exclusões ainda persistentes na sociedade.

Constitucionalmente, a educação é um direito de todos. Logo, é preciso promover, além do acesso ao educando com deficiência, a sua permanência na escola, com qualidade e equidade, em um espaço que privilegie a coletividade e que acolha com respeito a todos, considerando o ritmo de aprendizagem de cada educando e suas diferenças individuais.

Nesse sentido, pode-se aprender com o CIEJA Campo Limpo como promover práticas de inclusão e emancipação do educando, considerando-se a diversidade, atrelando-se a educação ao objetivo emancipatório e inclusivo proposto por Freire. Torna-se necessário, portanto, repensar as práticas educativas, tendo como foco ações mais humanas, democráticas e equitativas, com ações e discursos em prol da consciência e da libertação. Assim, é imprescindível se aproximar de Paulo Freire, quando se pensa e se quer um fazer pedagógico consciente, quando se pensa e se quer escolas regulares que trabalhem com práticas verdadeiramente libertadoras e inclusivas.

\section{Referências}

BRASIL. Presidência da República. Decreto N 6.949, de 25 de agosto de 2009 - Promulga a Convenção Internacional sobre os Direitos das Pessoas com Deficiência e seu Protocolo facultativo, assinado em Nova York, em 30 de março de 2007. . Ministério da Educação. Secretaria de Educação Especial. Política Nacional de Educação Especial na perspectiva da Educação Inclusiva. Brasília: MEC/SEESP, 2008.

. Lei no 13.146, de 6 de julho de 2015. Institui a Lei Brasileira de Inclusão da Pessoa com Deficiência (Estatuto da Pessoa com Deficiência).COSTA, M. P. R.; TURCI, P. C. Inclusão Escolar na perspectiva da educação para todos de Paulo Freire. VII Encontro da Associação Brasileira de Pesquisadores em Educação Especial. Londrina - 08 a 10 Novembro de 2011. 
FACCI, M. G.D.; MEIRA, M. E. M.; TULESKI, S. C. (Orgs.). A exclusão dos "incluídos": uma crítica da psicologia da educação à patologização e medicalização dos processos educativos. Maringá: Eduem, 2011.

FREIRE, P. Pedagogia da autonomia: saberes necessários à prática educativa. 22 ed. São Paulo: Paz e Terra, 2003.

A educação na cidade. São Paulo: Editora Cortez, 2001.

Pedagogia da Tolerância. São Paulo: Paz e Terra, 2004.

Pedagogia do oprimido. 17ed. Rio de Janeiro: Paz e Terra, 2013.

Pedagogia da esperança: um reencontro com a pedagogia do oprimido. Rio de Janeiro: Paz e terra, 2013.

GRAVATÁ André, et. al. Volta ao mundo em 13 escolas. São Paulo: Fundação Telefônica: A. G., 2013.

MANTOAN, M.T.E. Inclusão escolar: o que é? Por quê? Como fazer? São Paulo: Moderna, 2003.

MANTOAN, M. T. E; BARANAUSKAS, Maria Cecília ; CARICO, Janaína Amorim. Todos nós - Unicamp acessível. In: MNANTOAN, Maria Teresa. E. (Org). O desafio das diferenças nas escolas. Petrópolis, RJ: Vozes, 2008.

MEDEIROS, M. da M. Direito de ser: formação e experiência na Educação de Jovens e Adultos. 2018. 84 f. Dissertação (Mestrado em Educação: História, Política, Sociedade) Programa de Estudos Pós-Graduados em Educação: História, Política, Sociedade, Pontifícia Universidade Católica de São Paulo, São Paulo, 2018.

SÃO PAULO (SP). Secretaria Municipal de Educação. Coordenadoria Pedagógica. CIEJAs na cidade de São Paulo: identidades, culturas e histórias. São Paulo : SME / COPED, 2020.

SEVERINO, A. J. Metodologia do trabalho científico. 23 ed. rev. e atual. São Paulo: Cortez, 2007.

Toledo, A. L. B. S. de. Educação de Jovens e Adultos (EJA): um estudo sobre a inclusão de adolescentes no Centro Integrado de Educação de Jovens e Adultos (CIEJA). 2017. 95 f. Dissertação (Mestrado) - Universidade Nove de Julho - UNINOVE, São Paulo, 2017

UNESCO. Declaração mundial sobre educação para todos e plano de ação para satisfazer as necessidades básicas de aprendizagem. Jomtien, Tailândia: UNESCO, 1990.

UNESCO. Declaração de Salamanca: Sobre Princípios, Políticas e Práticas na Área das Necessidades Educativas Especiais. Salamanca-Espanha,1994.

Recebido em: 10/08/2021

Aceito em: 29/09/2021 